\title{
Incidence and risk factors of retinopathy of prematurity in an Italian cohort of preterm infants
}

\author{
Carlo Dani ${ }^{1,2^{*}}$, Caterina Coviello ${ }^{1}$, Fiorenza Panin ${ }^{1}$, Saverio Frosini ${ }^{3}$, Simonetta Costa ${ }^{4}$, Velia Purcaro ${ }^{4}$, \\ Domenico Lepore ${ }^{5}$ and Giovanni Vento ${ }^{4}$
}

\begin{abstract}
Objective: Non-negligible differences in retinopathy of prematurity (ROP) and its risk factors between different neonatal intensive care units (NICUs) are reported. Our aim was to assess the incidence and risk factors for ROP development in a large cohort of very preterm infants who were assisted in two Italian NICUs.

Methods: Preterm infants with gestational age between $23^{+0}$ and $29^{+6}$ weeks were stratified into subgroups of infants who developed ROP and those who did not; their clinical characteristics were compared with univariate and multivariable logistic regression analyses.

Results: We studied a total of 178 infants of whom 67 (38\%) developed ROP (stage 1: $n=12$; stage 2: $n=41$; stage 3: $n=14)$. Regression analysis demonstrated that maternal milk (OR $0.979,95 \% \mathrm{Cl} 0.961-0.998)$ decreased the risk of developing ROP, while intraventricular hemorrhage (IVH) (OR 2.055, 95\% Cl 1.120-3.772) increased it. Moreover, maternal milk was found to decrease (OR 0.981, 95\% Cl 0.964-0.997) the risk of ROP at discharge, while RBC transfusion increased it (OR 1.522, 95\% Cl 1.208-1.916).

Conclusions: In our cohort the occurrence of ROP was similar to that previously reported. Strategies for promoting the use of mother's own milk, preventing IVH, and standardizing the approach to RBC transfusions could contribute to decreasing the risk of ROP in very preterm infants.
\end{abstract}

Keywords: Retinopathy of prematurity, Risk factors, Human milk, Interventricular hemorrhage, Preterm infants

\section{Background}

Retinopathy of prematurity (ROP) is a vasoproliferative retinal disorder, which is the main cause of visual impairment and blindness in preterm infants [1]. It has been reported that some stages of ROP occur in $40-50 \%$ of infants born $\leq 30$ weeks of gestational age, while severe ROP occurs in $7-8 \%$, and treatment is needed in $5-6 \%[2]$.

\footnotetext{
* Correspondence: cdani@unifi.lt

'Division of Neonatology, Careggi University Hospital, Largo Brambilla 3, 50141 Florence, Italy

2Department of Neurosciences, Psychology, Drug Research and Child Health, Careggi University Hospital of Florence, Florence, Italy

Full list of author information is available at the end of the article
}

ROP is a two phase disease with a first phase of reduced retinal vascular growth and loss of blood vessels due to a lack of growth factors and abnormal oxygenation $[3,4]$. During this phase, the retina is incompletely vascularized with the development of a peripheral avascular zone which becomes increasingly hypoxic. This hypoxia induces the second phase of ROP characterized by an increase in the expression of the vascular endothelial growth factor (VEGF) which can promote uncontrolled neovascularization and retinal detachment $[3,4]$.

The most common treatment of severe ROP is retinal ablation using laser photocoagulation to reduce VEGF production of the hypoxic peripheral retina, but this 
treatment destroys approximately two-thirds of the retina $[3,5]$. Over the last few years, intravitreal injections of anti-VEGF have emerged as an effective first-line treatment for severe ROP, and many authors have reported favourable outcomes using these drugs $[2,3,6]$.

Recently, many studies have investigated risk factors and co-morbidities associated to ROP [7-14], but it is worth noting that large differences in ROP frequency are reported between different neonatal intensive care units (NICUs). Moreover, it is important to observe that risk factors have a significant etiopathogenetic effect in some units or countries while in other settings they do not. This suggests that changes in neonatal assistance could contribute to the decreasing the occurrence of ROP and that evaluation of local risk factors is necessary for correction and possible prevention of this severe complication.

Thus, the purpose of this study was to assess the incidence of ROP and to investigate risk factors for its development in a large cohort of very preterm infants who were assisted in two Italian neonatal intensive care units (NICUs). Our aim was also to compare these risk factors to those individuated in previous studies and, possibly, to individuate proper strategies to limit their effects.

\section{Methods}

\section{Study population}

This retrospective study was carried out at the third level NICUs of Careggi University Hospital of Florence and Fondazione Policlinico Universitario A. Gemelli of Rome, after the approval of local ethics committees. These NICUs assist about 3300 and 4000 newborns per year and have 16 and 10 beds for neonatal intensive care, respectively. Moreover, in these NICUs about 50 and 40 preterm infants are born with gestational age $<30$ weeks per year, respectively, and there are about 0.5 cases of perinatal asphyxia per 1000 live births per year.

Infants were included in the study if they were born between $23^{+0}$ and $29^{+6}$ weeks of gestation. Exclusion criteria were major congenital malformations, chromosomal disorders, inherited metabolic diseases, and death before ROP screening.

\section{Study design}

Serial eye examinations were performed by boardcertified consultant ophthalmologists; the first examination was made according to the recommendation of the American Academy of Pediatrics on ROP screening [15]. ROP staging was performed in agreement with international classification [16]. When examination was normal, subsequent controls were scheduled every two weeks until complete retinal vascularization; if the vascularization was limited to zone 1 or in case of stage 1 and 2 the next ROP controls were weekly; in case of more severe forms of ROP (stage $\geq 3$ or plus diseases) eye examinations were performed several times a week at the discretion of the ophthalmologist. Eye examinations were performed through indirect ophthalmoscopy. The RetCam Imaging System II (Clarity Medical Systems, Pleasanton, CA) was used to confirm diagnosis, monitor disease and treatment, evaluate retinal neovascularization, and to take fundus photography in any grade ROP.

Clinical and demographic data were collected by reviewing patients' medical records. For each studied infant, we reported the diagnosis of ROP, age at diagnosis, its stage, possible treatment, and outcome. Moreover, the following data were recorded: gestational age, birth weight, birth weight $<10^{\circ}$ percentile, birth weight $Z$ score, sex, Apgar score at 5 min, mode of delivery, need and duration of noninvasive respiratory support [high-flow nasal cannulae (HFNC), nasal continuous airway pressure (NCPAP), bilevel NCPAP (BiPAP), nasal intermittent mechanical ventilation (N-IMV)], and mechanical ventilation [patient-triggered ventilation or high frequency ventilation (HFV)]; number of red blood cell (RBC) transfusions, treatment with sildenafil, weight percentile at 36 weeks of postmenstrual age, percentage of human, maternal, and formula milk administered during hospital stay, occurrence of PDA requiring treatment, sepsis, bronchopulmonary dysplasia (BPD), necrotizing enterocolitis (NEC), intraventricular hemorrhage (IVH), periventricular leukomalacia (PVL), duration of hospital stay, and death. To evaluate birth percentile INeS growth charts were used [17]; RBC transfusions were decided according to the guidelines of the Italian Society of Neonatology [18]; BPD was defined as oxygen requirement at 36 weeks of post-menstrual age [19]; PDA was diagnosed by echocardiography; NEC was diagnosed according to Bell's criteria [20]; sepsis was defined as positive blood culture; IVH was classified according to the Papile's classification scheme [21]; and PVL was diagnosed according to the De Vries' criteria [22].

All infants followed the same enteral nutrition protocol: trophic feeding was initiated within $24 \mathrm{~h}$ after birth and was continued at $20-40 \mathrm{~mL} / \mathrm{kg} / \mathrm{d}$ as tolerated for up to five days. Subsequently, the amount was increased by $20 \mathrm{ml} / \mathrm{kg}$ every day if enteral nutrition was tolerated. The goals for enteral nutrition were $150 \mathrm{~mL} / \mathrm{kg} / \mathrm{d}$ and $120 \mathrm{kcal} / \mathrm{kg} / \mathrm{d}$. Preterm formula was administered only when mother's or donor's human milk were not available.

The objective of respiratory support was to maintain $\mathrm{PaO}_{2}$ from 50 to $70 \mathrm{mmHg}, \mathrm{PaCO}_{2}$ less than $65 \mathrm{mmHg}$, $\mathrm{pH}>7.20$, and $\mathrm{SpO}_{2}$ from 90 to $95 \%$. Surfactant was given as early rescue treatment. 


\section{Statistical analysis}

The infants enrolled in the study were stratified into subgroups of infants who developed ROP or those who did not. Their clinical characteristics were described as mean and standard deviation, median and range, or rate and percentage. Normality of data distribution was assessed by ShapiroWilk's test. Parametric continuous variables were analyzed by the Student's " $\mathrm{t}$ " test or by Wilcoxon rank sum test in case of deviation from normality assumptions. Categorical variables were compared using the $\mathrm{X}^{2}$ test. $P<0.05$ was considered statistically significant.

A multivariable stepwise logistic regression analysis was performed to evaluate the potential independent effect of more important variables on the occurrence of ROP. We selected variables that at univariate analyses were different between the groups $(P<0.200)$ excluding those which were found to be collinear by calculating variance inflation factors (VIF). Thus, we assessed the effects of gestational age, birth weight (z-score), BPD, PDA, sepsis, NEC, IVH, PVL, RBC transfusions, maternal milk feeding, and treatment with sildenafil. A further multivariable stepwise logistic regression analysis was performed to evaluate the potential independent effect of the same variables on the ROP stage at discharge. Effect estimates were expressed as odds ratio (OR) with profile likelihood-based 95\% confidence limits.

Data analysis was performed using IBM SPSS Statistics version 20 (SPSS INC, Chicago, Illinois, USA).

\section{Results}

The study ran from November 2017 to March 2020. We studied a total of 178 infants of which 67 (38\%) developed any grade of ROP. Diagnosis of ROP was made at the mean post-menstrual age of $33.4 \pm 1.7$ weeks. Twelve $(18 \%)$ infants had stage 1 ROP, 41 (61\%) had was stage 2 ROP, and 14 (21\%) had stage 3 ROP. ROP staging at discharge is detailed in Table 1. Eleven (16\%) patients received intravitreal

Table 1 Stage of ROP at diagnosis and discharge in studied infants. Rate and (\%)

\begin{tabular}{lll}
\hline & $\begin{array}{l}\text { At diagnosis } \\
(\mathbf{n = 6 7 )}\end{array}$ & $\begin{array}{l}\text { At discharge }^{\mathbf{a}} \\
(\mathbf{n = 5 6 )}\end{array}$ \\
\hline Stage 1 & $12(18)$ & $7(12)^{\mathrm{b}}$ \\
Stage 2 & $41(61)$ & $33(59)^{\mathrm{c}}$ \\
Stage 3 & $14(21)$ & $16(29)^{\mathrm{d}}$ \\
Stage 4 & 0 & 0 \\
Stage 5 & 0 & 0 \\
\hline
\end{tabular}

a Six patients recovered from ROP; five patients were missed (four died and one was transferred to another hospital)

${ }^{\mathrm{b}}$ Five patients maintained the initial stage 1 ; two patients improved from stage 2

' Twenty-nine patients maintained the initial stage 1; two patients worsened from stage 1 ; two patients improved from stage 3

${ }^{d}$ Twelve patients maintained the initial stage 3 ; two patients worsened from stage 1 ; two patients worsened from stage 2 pharmacological treatment (9 ranibizumab, 1 bevacizumab, 1 afibercept).

Infants with ROP had lower gestational age, birth weight and birth weight z-score, more frequent need of respiratory support, RBC transfusions, and sildenafil, more frequent complications, such as BPD, PDA, NEC, and PVL, and longer duration of stay in hospital (Table 2).

Regression analysis demonstrated that maternal milk (OR 0.979, 95\% Cl 0.961-0.998) decreased the risk of developing ROP, while IVH (OR 2.055, 95\% Cl 1.120-

Table 2 Clinical characteristics of infants with and without ROP. Means \pm SD, or rate and (\%), or median and (IQR)

\begin{tabular}{|c|c|c|c|}
\hline & $\begin{array}{l}\text { ROP } \\
(n=67)\end{array}$ & $\begin{array}{l}\text { No ROP } \\
(n=111)\end{array}$ & $\mathbf{P}$ \\
\hline Gestational age (wks) & $26.6 \pm 1.8$ & $27.6 \pm 1.5$ & $<0.001$ \\
\hline Birth weight (g) & $887 \pm 268$ & $1043 \pm 262$ & $<0.001$ \\
\hline$<10^{\circ}$ percentile & $9(13)$ & $7(6)$ & $<0.001$ \\
\hline Z-score & $-0.05 \pm 1.06$ & $0.27 \pm 0.87$ & 0.874 \\
\hline Male & $30(44)$ & $57(51)$ & 0.720 \\
\hline Apgar score at 5 th $\min$ & $8(7-9)$ & $8(7-8)$ & 0.609 \\
\hline Antenatal steroids & $58(87)$ & $97(87)$ & 0.004 \\
\hline Caesarean section & $48(71)$ & $81(73)$ & 0.310 \\
\hline \multicolumn{4}{|l|}{ NIV } \\
\hline Duration (h) & $27.5(12.2-49.2)$ & $16(6-30)$ & 0.002 \\
\hline \multicolumn{4}{|l|}{ MV } \\
\hline Duration (h) & $4(0-21)$ & $0(0-2)$ & 0.029 \\
\hline RBC transfusions & $4.4 \pm 5.5$ & $1.6 \pm 2.5$ & $<0.001$ \\
\hline Sildenafil & $10(15)$ & $4(4)$ & \\
\hline Total dose (mg/kg) & $1.68 \pm 2.59$ & $0.12 \pm 0.57$ & $<0.001$ \\
\hline Duration (d) & $20.1 \pm 44.9$ & $0.10 \pm 0.51$ & $<0.001$ \\
\hline Maternal milk (\%) & $40.3 \pm 31.2$ & $68.2 \pm 31.1$ & $<0.001$ \\
\hline Human milk (\%) & $9.2 \pm 18.7$ & $7.5 \pm 13.2$ & 0.477 \\
\hline Formula milk (\%) & $50.3 \pm 29.6$ & $24.1 \pm 27.0$ & $<0.001$ \\
\hline Weight 36 weeks of PMA (g) & $1881 \pm 434$ & $1853 \pm 414$ & 0.691 \\
\hline Z-score & $-1.78 \pm 1.20$ & $-1.91 \pm 0.94$ & 0.434 \\
\hline PDA & $39(58)$ & $62(56)$ & 0.035 \\
\hline Sepsis & $26(39)$ & $35(31)$ & 0.053 \\
\hline BPD & $24(36)$ & $25(22)$ & 0.025 \\
\hline NEC & $7(10 \%)$ & $3(3 \%)$ & 0.048 \\
\hline \multicolumn{4}{|l|}{ IVH, } \\
\hline $1-2$ grade & $10(15 \%)$ & $13(12 \%)$ & 0.141 \\
\hline 3-4 grade & $11(16 \%)$ & $9(8 \%)$ & \\
\hline PVL & $13(19 \%)$ & $10(9 \%)$ & 0.011 \\
\hline Hospital stay (d) & $96.8 \pm 55.4$ & $65.0 \pm 30.2$ & $<0.001$ \\
\hline Mortality & $4(6 \%)$ & $15(13 \%)$ & 0.156 \\
\hline
\end{tabular}

NIV noninvasive ventilation, $M V$ mechanical ventilation, $R B C$ red blood cells, $P M A$ post-menstrual age, $P D A$ patent ductus arteriosus, $B P D$

bronchopulmonary dysplasia, NEC necrotizing enterocolitis, IVH intraventricular hemorrhage, $P V L$ periventricular hemorrhage 
3.772) increased it, after adjusting for gestational age, birth weight (z-score), BPD, PDA, sepsis, NEC, PVL, RBC transfusions, and treatment with sildenafil. Moreover, we found that maternal milk (OR 0.981, 95\% Cl 0.964-0.997) decreased the risk of ROP at discharge, while $\mathrm{RBC}$ transfusion (OR 1.522, 95\% Cl 1.208-1.916) increased it.

\section{Discussion}

In this study we evaluated the risk factors for ROP in a cohort of very preterm infants. We found an occurrence of any stage ROP of $38 \%$ which is similar to what has previously been reported [7-14]. In fact, epidemiological and cohort studies reported a ROP rate ranging from 23.2 [10] to $48.5 \%$ [12], with differences mainly due to different criteria for selecting studied populations.

We found that in our population the percentage of maternal human milk fed during infants' hospital stay was correlated to the risk of developing ROP (both at the time of screening and at discharge) and had a protective effect. This result is in agreement with previous studies demonstrating that feeding with mother's own milk can decrease the risk of ROP and severe ROP in very preterm infants $[23,24]$. In a recent meta-analysis of five studies [only randomized controlled studies (RCTs)] involving 2208 preterm infants, Zhu et al. demonstrated that exclusive human milk versus exclusive formula feeding decreases the risk of any stage (OR 0.25, 95\% $\mathrm{Cl} 0.13-0.49$ ) and severe ROP (OR 0.10, 95\% Cl 0.04-0.29), while mainly human milk versus mainly formula feeding decreases the risk of severe ROP (OR 0.16, 95\% Cl 0.06-0.43) [23]. Moreover, Miller et al., in a meta-analysis of 40 studies (6 RCTs and 34 observational studies) involving 8778 preterm infants, demonstrated that higher vs. lower dose human maternal milk intake decreases the risk of severe ROP (Risk ratio 0.82, 95\% Cl 0.70-0.98) [24].

Physiological mechanisms through which human milk may prevent the development of ROP may be the antioxidant [25] and immune-protective [26] properties of breastmilk. Human milk contains many antioxidant constituents, such as inositol, vitamin $C$, vitamin $E, \beta-$ carotene, and essential fatty acids [i.e. docosahexaenoic acid (DHA)] [27, 28]. Among immunomodulatory substances, human milk contains secretory immunoglobulin A, lactoferrin, lysozyme, cytokines, oligosaccharides, antioxidant enzymes, and cellular components [28-30]. Moreover, human milk encompasses higher concentrations of insulin-like growth factor 1 (IGF-1) than preterm formulas [31], and it has been demonstrated that preterm infants fed with human milk have higher serum levels of IGF-1 [32]. This is particularly important since it has been shown that IGF-1 is crucial for physiological retinal vascularization, and its lack can lead to impaired retinal vascularity and ROP [4]. On the other hand, our patients received fresh, pasteurized, and/or frozen/ thawed maternal milk and we are aware that these procedures may have changed its composition and affected the magnitude of its protective effect.

We found that the occurrence of any grade IVH increased the risk of ROP. This correlation was reported also by Yau et al. [10], while Chung et al. [12] found that IVH was correlated with the progression of ROP. This correlation can be explained by similar aspects of ROP and IVH pathogenesis, such as the vascular immaturity of retina and germinal matrix [33], and the role of oxidative stress induced by blood flow and oxygen delivery fluctuations which could promote hypoxic-ischemic and re-perfusion injuries and the development of these complications [34]. We did not find a correlation between IVH occurrence and the ROP at discharge. Therefore, our results suggest that IVH can favor the development of ROP but cannot affect its progression to worsening or improvement. Unfortunately, our data cannot explain why IVH can promote the development of ROP but not its outcome at discharge.

RBC transfusions was found to be a risk factors for ROP at discharge but not at the screening visit. This is consistent with the fact that the majority of transfusions for anemia of prematurity are performed after first weeks of life and, therefore, it can be speculated that they affect the progression of ROP rather than its onset. This correlation between RBC transfusions and ROP confirm previous findings $[35,36]$ which have been explained by the pro-oxidant effect of transfusions due to the increase in oxygen delivery to the retina secondary to increased packed cell volume and lower oxygen affinity of adult haemoglobin in packed red cells (PRCs), and secondary iron overload [37].

In our study, we could not demonstrate a role of gestational age and/or birth weight as risk factors for ROP as shown in previous studies [7-14]. This might depend on several factors, such as differences in studied populations, different model used for multivariable data analysis (i.e.: our model included the amount of human milk feeding and treatment with sildenafil which were not included in previous studies [7-14]), and a lack of severe ROP (>3rd stage) in our population. Thus, it is possible that the protective effect of human milk counteracted the detrimental effect of low gestational age and/or birth weight on ROP risk.

Limitations of our study include small sample size, variable medical and nursing care over time and between care teams and units, its retrospective design which precludes the possibility of assessing the role of other previously reported risk factors for ROP [38]. In particular, we did not evaluate some maternal factors because their role is controversial (i.e.: hypertensive disorders of 
pregnancy, premature rupture of membranes, chorioamnionitis, maternal diabetes, medications, age [38]) or because some data were not available (i.e.: maternal smoking, iron deficiency, anemia, blood leukocyte count [35]). Moreover, we did not evaluate some neonatal factors [38] because of their low (i.e: inhaled nitric oxide, erythropoietin, and dopamine treatment, hyperglycemia) or high (i.e.: caffeine treatment) occurrence in our population (unreported data) which did not allow comparisons between groups and evaluation of their possible effect. Another limitation of our study was the lack of severe ROP cases. This last point might decrease the comparability of our results with previous studies [714], but, on the other hand, this allowed us to highlight risk factors of mild-moderate cases of ROP which are commonly pooled with those of more severe cases assuming perhaps wrongly that they are the same.

\section{Conclusions}

In conclusion, we found that the occurrence of ROP in our cohort was similar to what has previously been reported, and that feeding very preterm infants with higher volumes of maternal milk decreased the risk of its development while IVH occurrence increased it. Moreover, we found that maternal milk decreased the risk of ROP at discharge, while RBC transfusions increased it. These results suggest that effective strategies for promoting the use of mother's own milk [39], preventing IVH [40], and standardizing the approach to RBC transfusions [18] can contribute to decreasing the risk of ROP in very preterm infants.

\begin{abstract}
Abbreviations
BiPAP: bi-level NCPAP; BPD: bronchopulmonary dysplasia; HFNC: high-flow nasal cannulae; IVH: intraventricular hemorrhage; HFV: high frequency ventilation; NCPAP: nasal continuous airway pressure; N-IMV: nasal intermittent mechanical ventilation; NEC: necrotizing enterocolitis; NICUs: neonatal intensive care units; RBC: number of red blood cell; PVL: periventricular leukomalacia; ROP: retinopathy of prematurity; VIF: variance inflation factors; VEGF: vascular endothelial growth factor
\end{abstract}

\section{Acknowledgements}

None.

\section{Authors' contributions}

CD, CC, SF, DL, and GV conceived the study. CD wrote the manuscript. CC, FP, SC, and VP collected data. All authors analyzed and interpreted patients' data, read and approved the final manuscript.

\section{Funding}

The study was performed without specific funds.

\section{Availability of data and materials}

The datasets used and/or analysed during the current study are available from the corresponding author on reasonable request.

\section{Declarations}

\section{Ethics approval and consent to participate}

Local ethics committees approved the study. Parental consent was not required because this is a retrospective study and data were anonymized.
Consent for publication

Not applicable.

\section{Competing interests}

The authors declare that they have no competing interests.

\section{Author details}

'Division of Neonatology, Careggi University Hospital, Largo Brambilla 3, 50141 Florence, Italy. ${ }^{2}$ Department of Neurosciences, Psychology, Drug Research and Child Health, Careggi University Hospital of Florence, Florence, Italy. ${ }^{3}$ Eye Clinic, Neuromuscular and Sense Organs Department, Careggi University Hospital, Florence, Italy. ${ }^{4}$ Division of Neonatology, Department of Woman and Child Health and Public Health, Fondazione Policlinico Universitario A. Gemelli, IRCCS, Catholic University of Sacred Heart, Rome, Italy. ${ }^{5}$ Department of Ophthalmology, Gemelli Foundation IRCSS, Catholic University of the Sacred Heart, Rome, Italy.

Received: 3 November 2020 Accepted: 26 February 2021

Published online: 12 March 2021

\section{References}

1. Drack AV. Preventing blindness in premature infants. N Engl J Med. 1998; 338:1620-1.

2. Jefferies AL, Canadian Paediatric Society, Fetus and Newborn Committee. Retinopathy of prematurity: An update on screening and management. Paediatr Child Health. 2016;21:101-4.

3. Hellström A, Hård AL. Screening and novel therapies for retinopathy of prematurity. A review. Early Hum Dev. 2019;138:104846.

4. Smith LEH. Pathogenesis of retinopathy of prematurity. Growth Hormon IGF Res. 2004;14:S140-4.

5. Dani C, Frosini S, Fortunato P, Bertini G, Pratesi S, Pollazzi L, et al. Intravitreal bevacizumab for retinopathy of prematurity as first line or rescue therapy with focal laser treatment. A case series. J Matern Fetal Neonatal Med. 2012; 25:2194-7.

6. Frosini S, Franco F, Vicini G, Nicolosi C, Varriale G, Dani C, et al. Efficacy and safety of intravitreal bevacizumab for the treatment of retinopathy of prematurity: a single-center retrospective review. J Matern Fetal Neonatal Med. 2020;15:1-6.

7. Holmström G, Broberger U, Thomassen P. Neonatal risk factors for retinopathy of prematurity--a population-based study. Acta Ophthalmol Scand. 1998;76:204-7.

8. Shah VA, Yeo CL, Ling YLF, Ho LY. Incidence, risk factors of retinopathy of prematurity among very low birth weight infants in Singapore. Ann Acad Med Singap. 2005;34:169-78.

9. Akkoyun I, Oto S, Yilmaz G, Gurakan B, Tarcan A, Anuk D, et al. Risk factors in the development of mild and severe retinopathy of prematurity. J AAPOS. 2006:10:449-53.

10. Yau GSK, Lee JWY, Tam VTY, Liu CCL, Yip S, Cheng E, et al. Incidence and Risk Factors of Retinopathy of Prematurity From 2 Neonatal Intensive Care Units in a Hong Kong Chinese Population. Asia Pac J Ophthalmol (Phila). 2016:5:185-91.

11. Bas AY, Demirel N, Koc E, Isik DU, Hirfanoglu IM, Tunc T, TR-ROP Study Group. Incidence, risk factors and severity of retinopathy of prematurity in Turkey (TR-ROP study): a prospective, multicentre study in 69 neonatal intensive care units. Br J Ophthalmol. 2018;102:1711-6.

12. Chang JW. Risk factor analysis for the development and progression of retinopathy of prematurity. PLoS One. 2019;14:e0219934.

13. Mehner LC, Wagner BD, Bol KA, Singh JK, Oliver SC, Patnaik JL, et al. Trends in retinopathy of prematurity over 12 years in a Colorado cohort. Ophthalmic Epidemiol. 2020;7:1-7.

14. Grottenberg BG, Korseth KM, Follestad T, Stensvold HJ, Støen R, Austeng D. Stable incidence but regional differences in retinopathy of prematurity in Norway from 2009 to 2017. Acta Ophthalmol. 2020. Online ahead of print. https://doi.org/10.1111/aos.14593.

15. Fierson WM, American Academy of Pediatrics section on ophthalmology. Screening examination of premature infants for retinopathy of prematurity. Pediatrics. 2018;142:e20183061.

16. International Committee for the Classification of Retinopathy of Prematurity. The international classification of retinopathy of prematurity revisited. Arch Ophthalmol. 2005;123:991-9. 
17. Bertino E, Di Nicola P, Varalda A, Occhi L, Giuliani F, Coscia A. Neonatal growth charts. J Matern Fetal Neonatal Med. 2012;25S1:67-9.

18. Girelli G, Antoncecchi S, Casadei AM, Del Vecchio A, Isernia P, Motta M, et al. Recommendations for transfusion therapy in neonatology. Blood Transfus. 2015;13:484-97.

19. Ehrenkranz RA, Walsh MC, Vohr BR, Jobe AH, Wright LL, Fanaroff $A A$, et al. Validation of the National Institutes of Health consensus definition of bronchopulmonary dysplasia. Pediatrics. 2015;16:1353-60.

20. Bell MJ, Ternberg JL, Feigin RD, Keating JP, Marshall R, Barton L, et al. Neonatal necrotizing enterocolitis: therapeutic decisions based on clinical staging. Ann Surg. 1978;187:1-7.

21. Papile LS, Burstein J, Burstein $R$, Koffler $H$. Incidence and evolution of the subependymal intraventricular hemorrhage: a study of infants weighing less than 1500 grams. J Pediatr. 1978;92:529-34.

22. De Vries LS, Eken P, Dubowitz LM. The spectrum of leukomalacia using cranial ultrasounds. Behav Brain Res. 1992;49:1-6.

23. Zhou J, Shukla W, John D, Chen C. Human milk feeding as a protective factor for retinopathy of prematurity: a meta-analysis. Pediatrics. 2015;136: e1576-86.

24. Miller J, Tonkin E, Damarell RA, McPhee AJ, Suganuma M, Suganuma $H$, et al. A systematic review and meta-analysis of human Milk feeding and morbidity in very low birth weight infants. Nutrients. 2018;10:707.

25. Cloetens L, Panee J, Åkesson B. The antioxidant capacity of milk—the application of different methods in vitro and in vivo. Cell Mol Biol. 2013;59: 43-57.

26. Perrin MT, Fogleman A, Allen JC. The nutritive and immunoprotective quality of human milk beyond 1 year postpartum: are lactation-duration based donor exclusions justified? J Hum Lact. 2013;29:341-9.

27. Elisia I, Kitts DD. Differences in vitamin $\mathrm{E}$ and $\mathrm{C}$ profile between infant formula and human milk and relative susceptibility to lipid oxidation. Int J Vitam Nutr Res. 2013;83:311-9.

28. Aycicek A, Erel O, Kocyigit A, Selek S, Demirkol MR. Breast milk provides better antioxidant power than does formula. Nutrition. 2006;22:616-9.

29. Baydas G, Karatas F, Gursu MF, Ayse Bozkurt H, Ilhan N, Yasar A, et al. Antioxidant vitamin levels in term and preterm infants and their relation to maternal vitamin status. Arch Med Res. 2002;33:276-80.

30. L'Abbe MR, Friel JK. Superoxide dismutase and glutathione peroxidase content of human milk from mothers of premature and full-term infants during the first 3 months of lactation. J Pediatr Gastroenterol Nutr. 2000;31: 270-4.

31. Nagashima K, Itoh K, Kuroume T. Levels of insulin-like growth factor I in fulland preterm human milk in comparison to levels in cow's milk and in milk formulas. Biol Neonate. 1990;58:343-6.

32. Diaz-Gomez NM, Domenech E, Barroso F. Breast-feeding and growth factors in preterm newborn infants. J Pediatr Gastroenterol Nutr. 1997;24:322-7.

33. Brown DR, Biglan AW, Stretavsky MM. Retinopathy of prematurity: the relationship with intraventricular hemorrhage and bronchopulmonary dysplasia. J Pediatric Ophthalmol Strabismus. 1990;27:268-71.

34. O'Keefe M, Kafil-Hussain N, Flitcroft I, Lanigan B. Ocular significance of intraventricular haemorrhage in premature infants. Br J Ophthalmol. 2001; 85:357-9.

35. Slidsborg C, Jensen A, Forman JL, Fledelius HC, Greisen G, Cour M. Neonatal risk factors for treatment-demanding retinopathy of prematurity: a Danish National Study. Ophthalmology. 2016;123:796-803.

36. Bas AY, Demirel N, Koc E, Isik DU, Hirfanoglu IM, Tunc T. Incidence, risk factors and severity of retinopathy of prematurity in Turkey (TR-ROP study): a prospective, multi-Centre study in 69 neonatal intensive care units. $\mathrm{Br}$ J Ophthalmol. 2018;102:1711-6.

37. Villeneuve A, Arsenault V, Lacroix J, Tucci M. Neonatal red blood cell transfusion. Vox Sang. 2020. Online ahead of print. https:/doi.org/10.1111/vox.13036.

38. Kim SJ, Port AD, Swan R, Campbell JP, Chan RVP, Chiang MF. Retinopathy of prematurity: a review of risk factors and their clinical significance. Surv Ophthalmol. 2018;63:618-37.

39. Tambani E, Giannì ML, Bezze EN, Sannino P, Sorrentino G, Plevani L, et al. Exploring the gap between needs and practice in facilitating breastfeeding within the neonatal intensive care setting: an Italian survey on organizational factors. Front Pediatr. 2019;7:276.

40. Ballabh P. Pathogenesis and prevention of intraventricular hemorrhage. Clin Perinatol. 2014;41:47-67.

\section{Publisher's Note}

Springer Nature remains neutral with regard to jurisdictional claims in published maps and institutional affiliations.

\section{Ready to submit your research? Choose BMC and benefit from:}

- fast, convenient online submission

- thorough peer review by experienced researchers in your field

- rapid publication on acceptance

- support for research data, including large and complex data types

- gold Open Access which fosters wider collaboration and increased citations

- maximum visibility for your research: over $100 \mathrm{M}$ website views per year

At $\mathrm{BMC}$, research is always in progress.

Learn more biomedcentral.com/submissions 